05;06

\title{
Морфологические превращения \\ в нанофазном смачивающем слое меди \\ на кремнии, активированные \\ воздействием зонда атомно-силового \\ микроскопа
}

\author{
(c) Н.И. Плюснин, А.М. Маслов
}

Институт автоматики и процессов управления ДВО РАН, Владивосток, Россия

E-mail: plusnin@iacp.dvo.ru

Поступило в Редакцию 4 июля 2017 г.

С помощью атомно-силовой микроскопии на воздухе в нанофазном смачивающем слое $\mathrm{Cu}_{2} \mathrm{Si}$ на подложке $\mathrm{Si}(001)$ селективно активирован фазовый переход в более стабильный силицид $\mathrm{Cu}$. Этот переход сопровождался увеличением латерального размера зерен, их высоты и уменьшением их плотности. Полученный эффект может быть использован для формирования упорядоченных ансамблей наноостровков и нанолитографии.

DOI: 10.21883/PJTF.2018.05.45703.16950

Многие прикладные исследования в области наноиндустрии сфокусированы на нанофазных покрытиях благородных металлов и меди. Это объясняется их уникальными свойствами, в частности биосовместимостью, сочетающейся с поверхностно-усиленным комбинационным рассеянием. Кроме того, эти покрытия перспективны для каталитического ускорения химических реакций, нелинейной нанооптики и наноэлектроники. Для катализа особенно важна способность нанофазной меди самоочищаться от окисла при облучении светом [1]. Bсе это делает такие покрытия привлекательными объектами для наноиндустрии. Естественно возникает вопрос: возможно ли использование нанофазного слоя меди в нанотехнологиях, в том числе нанолитографии? В частности, возможен ли фазовый переход метастабильный нанофазный смачивающий слой-стабильная фаза под давлением зонда 
атомно-силового микроскопа и какова степень его пространственной селективности?

Эффект смачивания покрытием подложки проявляется при различии постоянных их решеток (или их атомной плотности), меньшем, чем критическая величина (9-14\% [2]), при этом смачивающий слой всегда псевдоморфный и повторяет структуру подложки $[3,4]$.

Однако в том случае, когда имеется значительное несоответствие решеток, смачивающий слой уже значительно деформирован [4]. При еще большем различии граница раздела между смачивающим слоем и подложкой становится некогерентной, ее свободная энергия сопоставима с энергией границы раздела с вакуумом [5], возникает неупругая (пластическая) деформация, дефектность слоя и образуются островкиагрегаты.

С увеличением разницы параметров решеток угол смачивания $\theta$ островков приближается к $90^{\circ}$ и происходит формирование покрытия, состоящего из деформированных нанокластеров, адаптированных к подложке по атомной плотности. Такой нанофазный смачивающий слой (HCC) можно отнести к двумерным нанофазным покрытиям [6,7], которые имеют нанофазную структуру в латеральных направлениях и являются метастабильными.

В предыдущих исследованиях [8] мы показали, что в покрытиях $\mathrm{Cu}$ на $\mathrm{Si}(001)$ при толщине 2-4 монослоя происходит формирование $\mathrm{HCC}$ состава $\mathrm{Cu}_{2} \mathrm{Si}$. Величина накопленной при росте энергии у $\mathrm{HCC}$ значительно выше, чем у обычного псевдоморфного смачивающего слоя. Поэтому следует ожидать переход НСС к стабильной фазе под давлением зонда атомно-силового микроскопа и модификацию его структуры и морфологии. Цель настоящей работы - показать, что данный эффект действительно существенно выражен в системе $\mathrm{Cu}-\mathrm{Si}(001)$ и что он приводит к значительным локализованным вдоль поверхности морфологическим изменениям.

Ранее были опубликованы данные электронной Оже-спектроскопии (ЭОС), спектроскопии характеристических потерь энергии электронов и атомно-силовой микроскопии (ACM) о росте $\mathrm{Cu}$ на подложке $\mathrm{Si}$ c прослойками $\mathrm{Fe}-\mathrm{Si}$ различной структуры [7]. Эти данные показывают, что происходит рост НСС меди при его низкотемпературном осаждении и что после выгрузки образцов на воздух, согласно исследованиям методом АСМ, этот слой собирается в крупные островки. Очевидно, что причина такой морфологической трансформации - выделение скрытой

2 Письма в ЖТФ, 2018, том 44, вып. 5 
энергии в слое меди. Подобная трансформация возможна и в $\mathrm{HCC} \mathrm{Cu}$ на чистой поверхности кремния в вакууме.

Мы решили инициировать эту трансформацию давлением зонда атомно-силового микроскопа и исследовать степень ее локальности. Для этого мы изучали поведение $\mathrm{HCC} \mathrm{Cu}_{2} \mathrm{Si}$ на $\mathrm{Si}(001) 2 \times 1$ в двух режимах АCM: контактном и полуконтактном. При этом чтобы исследовать границу первой области, размер области сканирования в контактном режиме был установлен в 2 раза меньшим, чем в полуконтактном режиме.

$\mathrm{HCC} \mathrm{Cu}_{2} \mathrm{Si}$ на $\mathrm{Si}(001) 2 \times 1$ был получен в сверхвысоковакуумной установке, оснащенной анализаторами ЭОС и дифракции медленных электронов (ДМЭ). Условия получения НСС $\mathrm{Cu}$ были аналогичными используемым в работах $[7,8]$. По данным ДМЭ, размер зерен слоя был меньше, чем длина когерентности первичных электронов $(\sim 20 \mathrm{~nm})$. В то же время, согласно данным ЭОС, НСС имел состав $\mathrm{Cu}_{2} \mathrm{Si}$, а его толщина была равна $\sim 0.6 \mathrm{~nm}$.

После получения образцов в вакууме и недельной выдержки их на воздухе (параметры воздуха: содержание кислорода $285-281 \mathrm{~g} / \mathrm{m}^{3}$; относительная влажность $63-82 \%$, температура $13-15^{\circ} \mathrm{C}$ ) они подвергались последовательному (интервал времени между снятием сканов составлял $1 \mathrm{~min}$ ) сканированию в атомно-силовом микроскопе „Solver P-47“ (фирма НТ-МДТ) в двух режимах: 1) в контактном режиме (размер скана: по точкам $512 \times 512$, физический размер $5 \times 5 \mu \mathrm{m})$; 2) в полуконтактном режиме (размер скана: по точкам $512 \times 512$, физический размер $10 \times 10 \mu \mathrm{m})$. Скорость сканирования составляла $10 \mu \mathrm{m} / \mathrm{s}$. Использовались АCM-кантилеверы марки NSG01 с TiN-покрытием (резонансная частота $87-230 \mathrm{kHz}$, постоянная жесткости 1.45-15.1 N/m). Калибровка силы воздействия зонда атомно-силового микроскопа на поверхность не производилась. В полуконтактном режиме были получены также сканы с фазовым контрастом. При этом производилось перемножение синуса фазового сдвига колебаний кантилевера $(\operatorname{Sin} \varphi)$ на амплитуду $(M a g)$ его колебаний (единица измерения $M a g \cdot \operatorname{Sin} \varphi-\mathrm{pA})$.

Режим фазового контраста (сдвига) наряду с упругими свойствами поверхности, отражает также адгезионные и электростатические силы, возникающие между АСМ-зондом и образцом, а также другие физикохимические свойства образца, которые так или иначе связаны с этими силами. Однозначная интерпретация фазового сдвига, как правило, сопряжена со значительными трудностями. Но тем не менее свойства

Письма в ЖТФ, 2018, том 44, вып. 5 
Изменение морфологических характеристик нанофазного смачивающего слоя $\mathrm{Cu}$ на $\mathrm{Si}(001)$ при сканировании в атомно-силовом микроскопе

\begin{tabular}{c|c|c|c|c}
\hline \multirow{2}{*}{$\begin{array}{c}\text { Номер } \\
\text { скана }\end{array}$} & \multicolumn{4}{|c}{ Характеристики зерен (агломератов) } \\
\cline { 2 - 5 } & $\begin{array}{c}\text { вредняя } \\
h, \mathrm{~nm}\end{array}$ & $\begin{array}{c}\text { диаметр после } \\
\text { процедуры деконволюции } \\
W_{D}, \mathrm{~nm}\end{array}$ & $\begin{array}{c}\text { плотность, } \\
\mu \mathrm{m}^{-2}\end{array}$ & $\begin{array}{c}\text { количество } \\
\text { зерен }\end{array}$ \\
\hline 1 & 0.3 & 30 & 130 & 3150 \\
2 & 2.2 & 90 & 20 & 320 \\
3 & 3.4 & 120 & 10 & 250
\end{tabular}

сдвига фазы на поверхности материала, из которого состоит образец, индивидуальны для каждого его состояния. Поэтому его можно использовать в качестве показателя фазового перехода.

Известно, что чистый кремний на воздухе покрывается окислом кремния толщиной $2 \mathrm{~nm}$ [9]. Как показали наши исследования, после выдержки (не более трех недель) на воздухе подложек $\mathrm{Si}$, покрытых $\mathrm{HCC} \mathrm{Cu}_{2} \mathrm{Si}$, ACM-картины, полученные в полуконтактном режиме, оставались четкими, а фазовый контраст не изменялся. Мы полагаем, что покрытия не окислялись или, как в случае [1], очищались дневным светом от окисла. Первоначальные АСМ-картины (см. таблицу, скан № 1), полученные в полуконтактном режиме до АСМ в контактном режиме, показали, что средняя высота рельефа покрытия составляла около $0.3 \mathrm{~nm}$ (при шероховатости $0.06 \mathrm{~nm}$ ). При этом средний диаметр и количество зерен составляли около $30 \mathrm{~nm}$ и 3150 соответственно.

На рис. 1 представлены изображения АСМ-картин, которые были последовательно получены в контактном $(a)$ и полуконтактном $(b-d)$ режимах в другой точке (сканы № 2 и 3 в таблице). Изображение на рис. $1, b$ показано в 3D-формате с наклонным освещением без обработки скана и даже без вычитания плоскости. Изображение на pис. $1, c$ - результат обработки скана, представленного на рис. $1, b$, а на рис. $1, d$ приведено изображение в фазовом контрасте после обработки. По ним можно сравнить совмещенные области контактного (квадрат в центре) и полуконтактного (за квадратом) режимов сканирования. При обработке использовались подпрограммы приложения фирмы НТ-МДТ „Nova 1915“: Data Transformation, Deconvolution, Statistics, Section

2* Письма в ЖТФ, 2018, том 44, вып. 5 

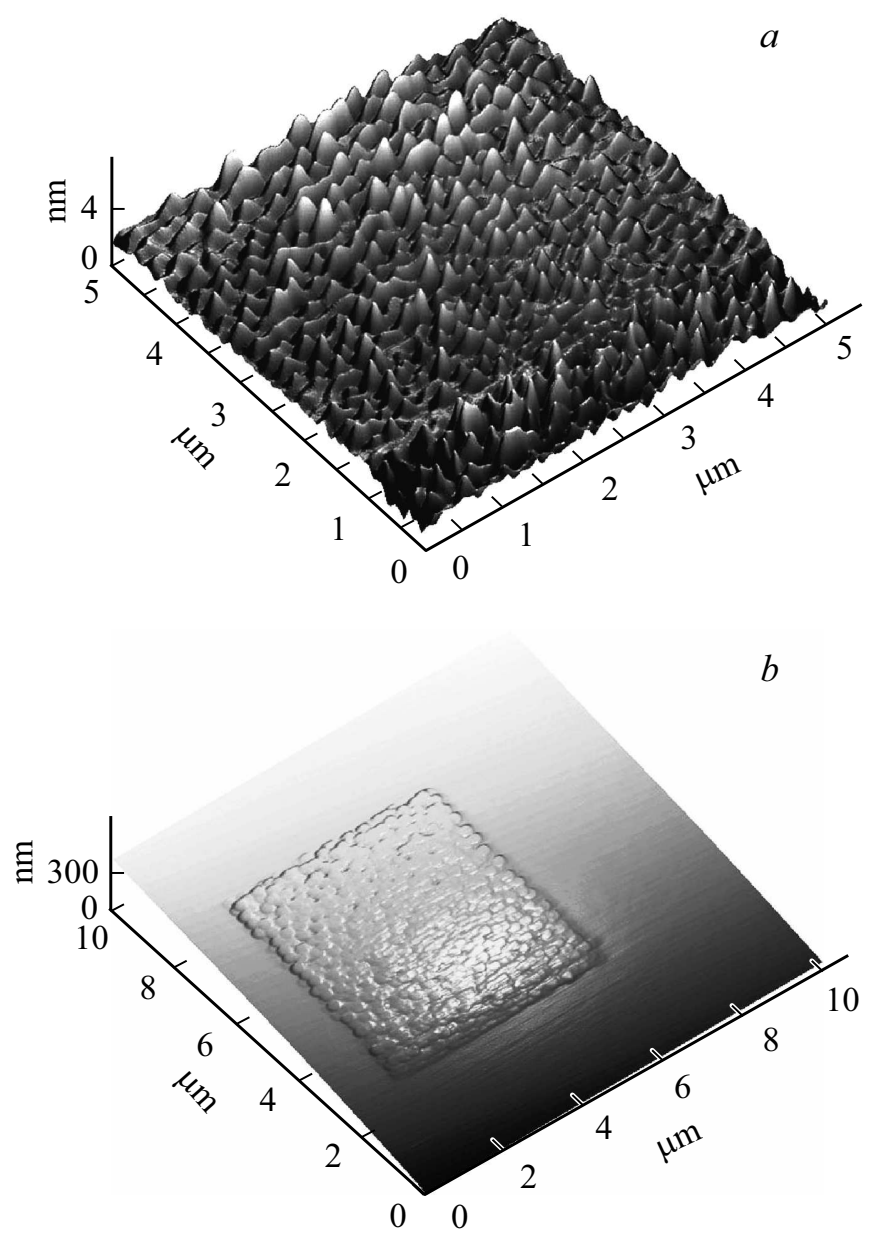

Рис. 1. Картины АCM, полученные на воздухе. $a$ - после получения в контактном режиме и обработки, $b-d-$ после последующего получения в полуконтактном режиме: без вычитания $(b)$ и с вычитанием $(c, d)$ наклона поверхности. $d-$ с инверсией картины фазового контраста (более высокая и светлая область соответствует меньшему фазовому сдвигу). Размер сканов $5 \times 5(a)$ и $10 \times 10 \mu \mathrm{m}(b-d)$.

Письма в ЖТФ, 2018, том 44, вып. 5 

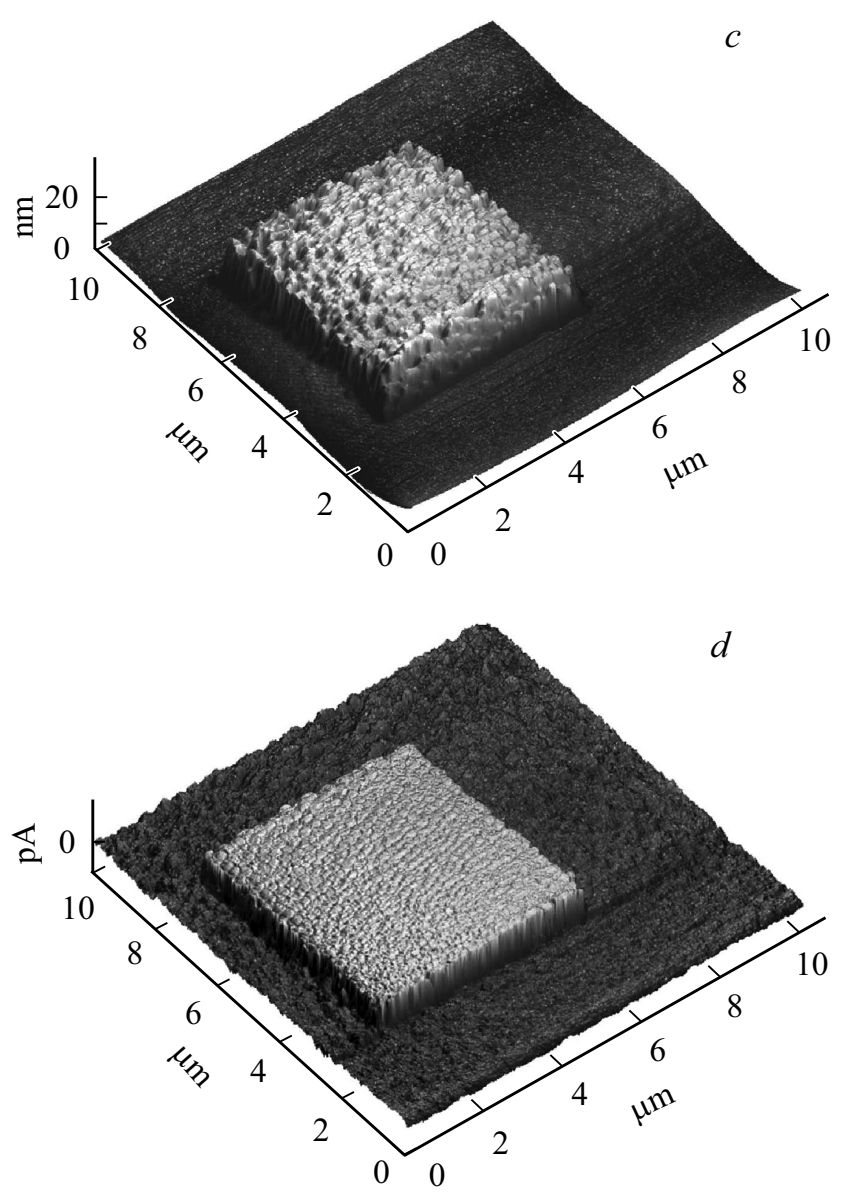

Рис. 1 (продолжение).

Analysis, Grain Analysis, a также процедуры вычитания плоскостей первого, второго и третьего порядков. Неровности, обусловленные шумами и макрорельефом, в случае необходимости (например, перед Grain Analysis) устранялись Фурье-фильтрованием.

После контактного сканирования зерна приобрели почти эллиптическую форму с латеральными размерами от $100 \mathrm{~nm}$ (по оси $Y$ ) до $200 \mathrm{~nm}$

Письма в ЖТФ, 2018, том 44, вып. 5 
(по оси $X$ ), как на рис. $1, b$. Мы думаем, что это кажущееся увеличение латерального размера зерен, которое произошло из-за налипания меди на зонд микроскопа при переходе. Действительно, после применения процедуры деконволюции (Deconvolution) с подгонкой формы и размера острия микроскопа размер зерен уменьшился (см. рис. 1, $a$ и таблицу, скан № 2). При этом по отношению к исходным (до контактного режима) значениям (см. таблицу, скан № 1) диаметр зерен изменился от 30 до $90 \mathrm{~nm}$, высота рельефа - от 0.3 до $2.2 \mathrm{~nm}$, а количество зерен - от 3150 до 320. Даже без учета изменения латерального размера значительное увеличение высоты зерен с уменьшением их количества указывает на фазовый переход с выделением скрытого тепла, в результате которого смачиваемость пленкой подложки уменьшилась и произошло изменение морфологии пленки.

Последующее получение АСМ-картин (скан № 3, $10 \times 10 \mu \mathrm{m}$ ) в полуконтактном режиме (рис. $1, b-d$ ) выявило различие высот рельефа и фазового запаздывания между областью контактной обработки (в центре) и областью за ее пределами. Как показывают данные таблицы (скан № 3), после дополнительного воздействия высота рельефа и диаметр зерен увеличились до 3.4 и $120 \mathrm{~nm}$ соответственно, а их количество уменьшилось до 250 . В полуконтактном режиме эти изменения вряд ли связаны с налипанием меди.

Результаты морфологического анализа (см. таблицу) без сомнения указывают на то, что после контактного сканирования произошла коалесценция зерен-островков в более крупные агрегаты: высота островков увеличилась, а их количество уменьшилось. При этом произошло латерально-селективное (с точностью до половины диаметра островков $90 \mathrm{~nm} / 2=45 \mathrm{~nm}$ ) возрастание высоты рельефа в $\sim 7$ раз $(2.2 \mathrm{~nm} / 0.3 \mathrm{~nm})$. С учетом указанного изменения высоты рельефа (рис. $1, c$ ), а также фазового сдвига (рис. $1, d$ ) нанофазное покрытие испытало фазовый переход в новую фазу, очевидно в фазу объемного силицида $\left(\mathrm{Cu}_{3} \mathrm{Si}\right)$.

Что касается влияния окислительной воздушно-капельной среды, то оно привело из-за окисления кремния к участию в составе покрытия кроме меди и кремния третьего химически активного компонента, а именно кислорода. Количество окисленного кремния, очевидно, лимитировано релаксацией напряжений на границе раздела новой фазы и подложки кремния, происходившей во время и после фазового перехода.

Письма в ЖТФ, 2018, том 44, вып. 5 

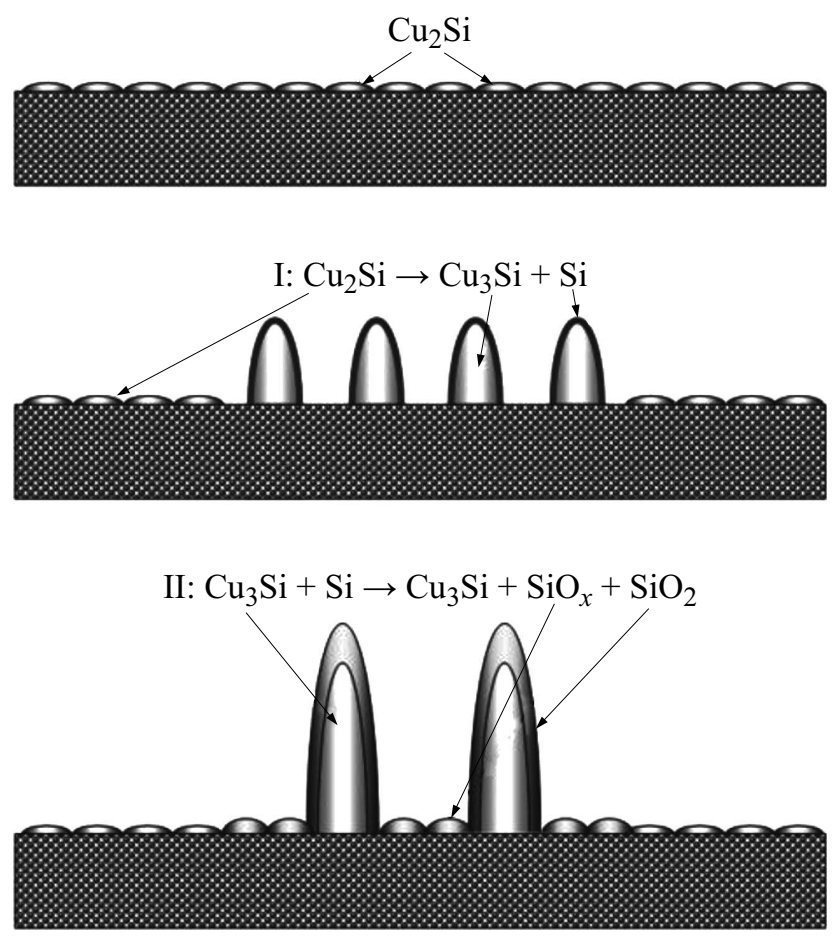

Рис. 2. Две стадии изменения состава и морфологии покрытия в результате воздействия соответственно зонда микроскопа (I - первая стадия) и воздушнокапельной среды воздуха (II - вторая стадия).

Действительно, при АСМ на влажном воздухе в области между зондом и поверхностью образца обычно присутствует капиллярная прослойка воды. А нанозерна (островки) силицида меди могут быть каталитическим активатором разложения воды на атомарный кислород и водород (см. [10]). Поэтому молекулы воды могут распадаться на атомы кислорода вблизи контакта наночастиц металла с острием зонда. В результате этого встречные потоки атомов кремния (из межзеренного пространства) и кислорода (в области вершин наночастиц) могут приводить к латеральному росту $\mathrm{SiO}_{2}$ на поверхности гранул. Поскольку при агломерации покрытия поверхность кремния оголяется, возможно

Письма в ЖТФ, 2018, том 44, вып. 5 
образование $\mathrm{SiO}_{x}$ в области между гранулами, как это наблюдалось на чистом кремнии в [9]. Рис. 2. схематически иллюстрирует стадии изменения рельефа покрытия после воздействия зонда и после окисления.

Таким образом, результаты исследования указывают на фазовый переход в нанофазном смачивающем слое силицида меди на кремнии после его селективной активации давлением зонда атомно-силового микроскопа на воздухе.

Авторы выражают благодарность В.М. Ильященко за помощь в подготовке образцов и С.А. Китань за помощь в их АСМ-сканировании.

Работа выполнена при частичной финансовой поддержке ФАНО по программе „Дальний Восток“ (госзадание № 0262-2015-0133).

\section{Список литературы}

[1] Marimuthu A., Zhang J., Linic S. // Science. 2013. V. 339. P. 1590-1593.

[2] Frank F.C., Van der Merwe J.H. // Proc. Roy. Soc. Lond. A. 1949. V. 198. P. 216-225.

[3] Болховитянов Ю.Б., Пчеляков О.П., Чикичев С.И. // УФН. 2001. V. 171. C. 689-715.

[4] Dupraz M., Poloni R., Ratter K., Rodney D., De Santis M., Gilles B., Beutier G., Verdier M. // Phys. Rev. B. 2016. V. 94. P. 235427.

[5] Роберте Д., Паунд Г.М. // Новое в исследовании поверхности твердого тела / Под ред. Т. Джайядевайя, Р. Ванселова. М.: Мир, 1977. С. 82.

[6] Плюснин Н.И. // Вестн. ДВО РАН. 2016. № 4 (188). С. 27-35.

[7] Плюснин Н.И., Тарима Н.И., Ильященко В.М., С.А. Китань С.А. // Письма в ЖТФ. 2012. Т. 38. В. 7. С. $48-55$.

[8] Плюснин Н.И., Ильященко В.М., Китань С.А., Тарима Н.А. // Поверхность. Рентгеновские, синхротронные и нейтронные исследования. 2011. № 8. C. $29-40$.

[9] Латымев А.В., Насимов Д.А., Щеглов Д.В. // Вестн. НГУ. Сер. Физика. 2009. T. 4. B. 1. C. 47-55.

[10] Rodriguez J.A., Liu P., Wang X., Wen W., Hanson J., Hrbek J., Pérez M., Evans J. // Catalys. Today. 2009. V. 143. P. 45-50. 